\title{
ANALISIS KUALITAS PELAYANAN PELANGGAN BENGKEL MOTOR “ABC" MENGGUNAKAN KONSEP SERVIS QUALITY DAN IMPORTANCE-PERFORMANCE ANALYSIS
}

\author{
Galuh Krisna Dewanti ${ }^{1}$ Hermanto $^{2}$ \\ Program Studi Teknik Industri FTMIPA Universitas Indraprasta PGRI \\ E-mail: galuhdewanti@gmail.com, hers3sm@gmail.com
}

\begin{abstract}
Abstrak
Sepeda motor di kenal di Indonesia sejak tahun 1893, bagi masyarakat sepeda motor masih menjadi alat transportasi yang murah dan mudah baik di perkotaan maupun pedesaan. Angka jutaan dari populasi kendaraan sepeda motor membutuhkan perawatan atau servis rutin agar motor tetap prima. Semakin banyak pengguna sepeda motor di Indonesia, semakin banyak pula bengkelbengkel non resmi yang bermunculan, bagi penyedia jasa, untuk dapat bersaing dengan penyedia jasa yang lain harus selalu menjaga kualitas pelayanan yang diberikan. Analisis dimensi kualitas pelayanan jasa terhadap kepuasan konsumen sangat diperlukan bagi perusahaan untuk memberi pelayanan yang sesuai dengan kebutuhan pelanggan. Tujuan dari penelitian ini adalah untuk menganalisis kualitas pelayanan bengkel motor "ABC", apakah sudah sesuai dengan yang diinginkan pelanggan. Pengukuran kualitas pelayanan menggunakan konsep SERVQUAL untuk mengetahui apakaha ada gap antara pelayanan yang tersdia dengan harapan yang konsumen. Kemudian menggunakan Importance Performance Analysis (IPA) untuk mencari prioritas perbaikan. Dari perhitungan servqual didapatkan hasil bahwa pelayanan bengkel "ABC" tidak berkualitas dan dari IPA diperoleh sebanyak 9 atribut yang menjadi prioritas perbaikan.
\end{abstract}

Kata kunci: Servqual, IPA dan Kualitas Pelayanan

\begin{abstract}
Motorcycle known in Indonesia since 1893, for the motorcycle community is still a means of transportation that is cheap and easy in both urban and rural. Millions of motorcycle population in need of care or routine servicing still excellent. More and more users of motorcycles in Indonesia, the more non-formal workshops that have sprung up, for service providers, to be able to compete with other service providers should always maintain the quality of services provided. Analysis dimensions of service quality on customer satisfaction is very necessary for the company to provide services that meet customer needs. The purpose of this study was to analyze the quality of service bike shop "ABC", whether it is in accordance with the customer wanted. Measurement of quality of service using the concept of SERVQUAL to know there is a gap between the of available services with consumer expectations. Then, using Importance Performance Analysis (IPA) to seek improvement priorities. From the calculations showed that the ministry servqual workshop "ABC" is not qualified and from IPA obtained by 9 attributes priority repairs.
\end{abstract}

Keywords: Servqual, IPA and Quality of Service

\section{PENDAHULUAN}

Berkembangnya sepeda motor dari tahun ke tahun makin meningkat, populasi kendaraan sepeda motor membutuhkan perawatan atau servis rutin agar motor tetap prima. Muncul bengkelbengkel servis sepeda motor baik resmi dan tak resmi salah satunya bengkel motor "ABC". Persaingan yang kompetitif mendorong para penyedia jasa untuk memikirkan bagaimana memberikan pelayanan yang sesuai dengan harapan mereka. Untuk meningkatkan kepuasan pelanggan, pihak bengkel perlu mengetahui bagaimana kualitas pelayanan bengkel Selain itu, periode enam bulan terakhir yaitu bulan April-September 2016, jumlah pelanggan yang masuk melakukan servis tidak memenuhi target dari manajemen bengkel. Target manajemen bengkel jumlah pelanggan tiap bulan 300 pelanggan. 
Perusahaan yang sukses dapat memuaskan konsumen mereka, dengan kata lain konsumen yang tidak puas akan mempengaruhi bisnis secara negatif. Pemuasan Konsumen harus disertai dengan pemantauan terhadap kebutuhan dan keinginan mereka. Untuk itu, perusahaan harus mempertimbangkan sisi kualitas pelayanan agar dapat memberi kepuasan kepada pelanggan sesuai dengan yang diinginkan pelanggan. Kualitas pelayanan jasa bersifat abstrak dan konsepnya sulit dipahami, karena adanya karakteristik yang unik pada jasa yaitu tidak berwujud, tidak dapat dipisahkan antara produksi dan konsumsi, variabilitasnya tinggi, tidak tahan lama dan tidak menyebabkan kepemilikan (Parasuraman, Zeithaml and Berry 1985).

Dalam penelitian ini, peneliti menganalisa kualitas pelayanan yang diberikan oleh bengkel, mengidentifikasi gap/kesenjangan antara keinginan pelanggan dan bisnis proses yang sedang berjalan dan kemudian mengusulkan perbaikan yang diharapkan dapat meningkatkan kembali jumlah pelanggan bengkel tersebut. Adapun metode yang digunakan untuk mengidentifikasi gap/kesenjangan menggunakan konsep Servqual. Dalam konsep servqual terdapat lima kesenjangan (gap) yang menyebabkan kegagalan penyampaian jasa yaitu kesenjangan antara pengharapan konsumen dan persepsi manajemen, kesenjangan antara persepsi manajemen dan spesifikasi kualitas jasa, kesenjangan antara spesifikasi dan kualitas jasa, kesenjangan antara penyampaian jasa dan komunikasi eksternal dan kesenjangan antara jasa yang dirasakan dan jasa yang diharapkan.

Setelah memperoleh data melalui servqual, kemudian data dianalisis menggunakan Importance Performance Analysis (IPA). Tujuan yang ingin dicapai dalam penelitian ini adalah Menganalisa kualitas pelayanan bengkel motor ABC. Kemudian Mengetahui atribut-atribut pelayanan yang menjadi prioritas perbaikan dan memberikan usulan perbaikan pelayanan yang sesuai dengan kebutuhan atau keinginan pelanggan.

\section{METODE PENELITIAN}

Objek dalam penelitian ini adalah pelanggan bengkel motor "ABC", yang telah melakukan servis sepeda motor minimal tiga kali servis di bengkel motor "ABC". Untuk megetahui kualitas pelayanan bengkel motor tersebut menggunakan konsep SERVQUAL. Dengan langkah menyebarkan kuesioner, ada dua kuesioner yaitu kuesioner persepsi dan kuesioner harapan (expectation). Kuesioner tersebut memuat 21 atribut pelayanan bengkel motor "ABC". Hasil kuesioner diolah menggunakan konsep SERVQUAL untuk mengetahui apakah ada perbedaan (gap) antara persepsi dan harapan konsumen terhadap pelayanan bengkel. Untuk mengetahui Gap tersebut menggunakan rumus:

$\mathrm{Q}=\mathrm{P}($ Perseived Service $)-\mathrm{E}($ Expected Service $)$

(1)

Untuk menentukan atribut yang menjadi prioritas perbaikan menggunakan konsep Importance

Performance Analysis (IPA)

\section{HASIL DAN PEMBAHASAN}

Tabel 1. Harapan, Persepsi, dan Gap Tiap Atribut

\begin{tabular}{lllll}
\hline \multirow{2}{*}{ Dimensi } & \multicolumn{1}{c}{ Atribut Layanan } & \multicolumn{2}{c}{ Customer Satisfaction } \\
\cline { 3 - 5 } & \multicolumn{1}{c}{ Persepsi } & Harapan & Gap \\
\hline \multirow{2}{*}{ Reliability } & Ketelitian pengerjaan oleh mekanik & 2.947 & 4.413 & -1.467 \\
& Keterampilan Mekanik & 2.667 & 4.493 & -1.827 \\
& $\begin{array}{l}\text { Kecekatan Mekanik dalam melayani } \\
\text { pelanggan }\end{array}$ & 2.693 & 4.480 & -1.787 \\
& $\begin{array}{l}\text { Jumlah mekanik sebanding dengan } \\
\text { kendaraan yang diservis }\end{array}$ & 2.747 & 4.520 & -1.773
\end{tabular}




\begin{tabular}{|c|c|c|c|c|}
\hline & Kelengkapan sparepart & 2.480 & 4.600 & -2.120 \\
\hline \multirow{3}{*}{ Responsiveness } & $\begin{array}{l}\text { Adanya penjelasan tentang kualitas suku } \\
\text { cadang asli dari pabrik dan yang tidak asli }\end{array}$ & 2.867 & 4.613 & -1.747 \\
\hline & $\begin{array}{l}\text { Kemudahan untuk memperoleh informasi } \\
\text { mengenai suku cadang }\end{array}$ & 3.107 & 4.440 & -1.333 \\
\hline & $\begin{array}{l}\text { Harga servis standard an system } \\
\text { pembayaran yang mudah dan cepat }\end{array}$ & 2.840 & 4.547 & -1.707 \\
\hline \multirow{6}{*}{ Assurance } & Kualitas servis yang diberikan & 2.733 & 4.493 & -1.760 \\
\hline & Kualitas sparepart yang terjamin & 2.800 & 4.520 & -1.720 \\
\hline & Kemudahan dalam memperoleh sparepart & 3.267 & 4.520 & -1.253 \\
\hline & Perasaan aman saat melakukan servis & 2.947 & 4.493 & -1.547 \\
\hline & $\begin{array}{l}\text { Pihak bengkel bertanggung jawab penuh } \\
\text { atas hasil service }\end{array}$ & 3.960 & 4.120 & -0.160 \\
\hline & Antrian servis yang teratur & 2.813 & 4.480 & -1.667 \\
\hline \multirow{3}{*}{ Emphaty } & Kemudahan pendaftaran ketika servis & 2.733 & 4.520 & -1.787 \\
\hline & $\begin{array}{l}\text { Pelayanan yang sopan dan ramah petugas } \\
\text { tempat penddaftaran servis }\end{array}$ & 3.520 & 4.533 & -1.013 \\
\hline & $\begin{array}{l}\text { Pelayanan yang sopan dan ramah dari para } \\
\text { mekanik }\end{array}$ & 2.573 & 4.533 & -1.960 \\
\hline \multirow{4}{*}{ Tangibles } & $\begin{array}{l}\text { Kelengkapan sarana hiburan pada ruang } \\
\text { tunggu (tv, majalah, Koran dll). }\end{array}$ & 2.880 & 4.413 & -1.533 \\
\hline & Tersedia minuman gratis & 2.933 & 4.493 & -1.560 \\
\hline & Kebersihan ruang tunggu & 2.880 & 4.480 & -1.600 \\
\hline & $\begin{array}{l}\text { Tingkat kenyamanan ruang tunggu (suhu, } \\
\text { kebisingan, dan pencahayaan) }\end{array}$ & 3.000 & 4.520 & -1.520 \\
\hline
\end{tabular}

Sumber: data primer pengolahan data

Table 2. Rekapitulasi Kualitas Pelayanan bengkel sepeda motor "ABC"

\begin{tabular}{|c|c|c|c|c|c|}
\hline \multirow{2}{*}{ Dimensi } & \multicolumn{2}{|c|}{ Rata-rata } & \multirow{2}{*}{ Gap } & \multirow{2}{*}{ Ranking } & \multirow{2}{*}{ Hasil } \\
\hline & Persepsi & Harapan & & & \\
\hline Reliability & 2.71 & 4.50 & -1.79 & 1 & Tidak berkualitas \\
\hline Responsiveness & 2.94 & 4.53 & -1.60 & 2 & Tidak berkualitas \\
\hline Assurance & 3.09 & 4.44 & -1.35 & 5 & Tidak berkualitas \\
\hline Emphaty & 2.94 & 4.53 & -1.59 & 3 & Tidak berkualitas \\
\hline
\end{tabular}


Tangible

2.94

4.48

$-1.53$

4

Tidak berkualitas

Sumber: data primer pengolahan data

\subsection{Hasil Importance Performance Analysis (IPA)}

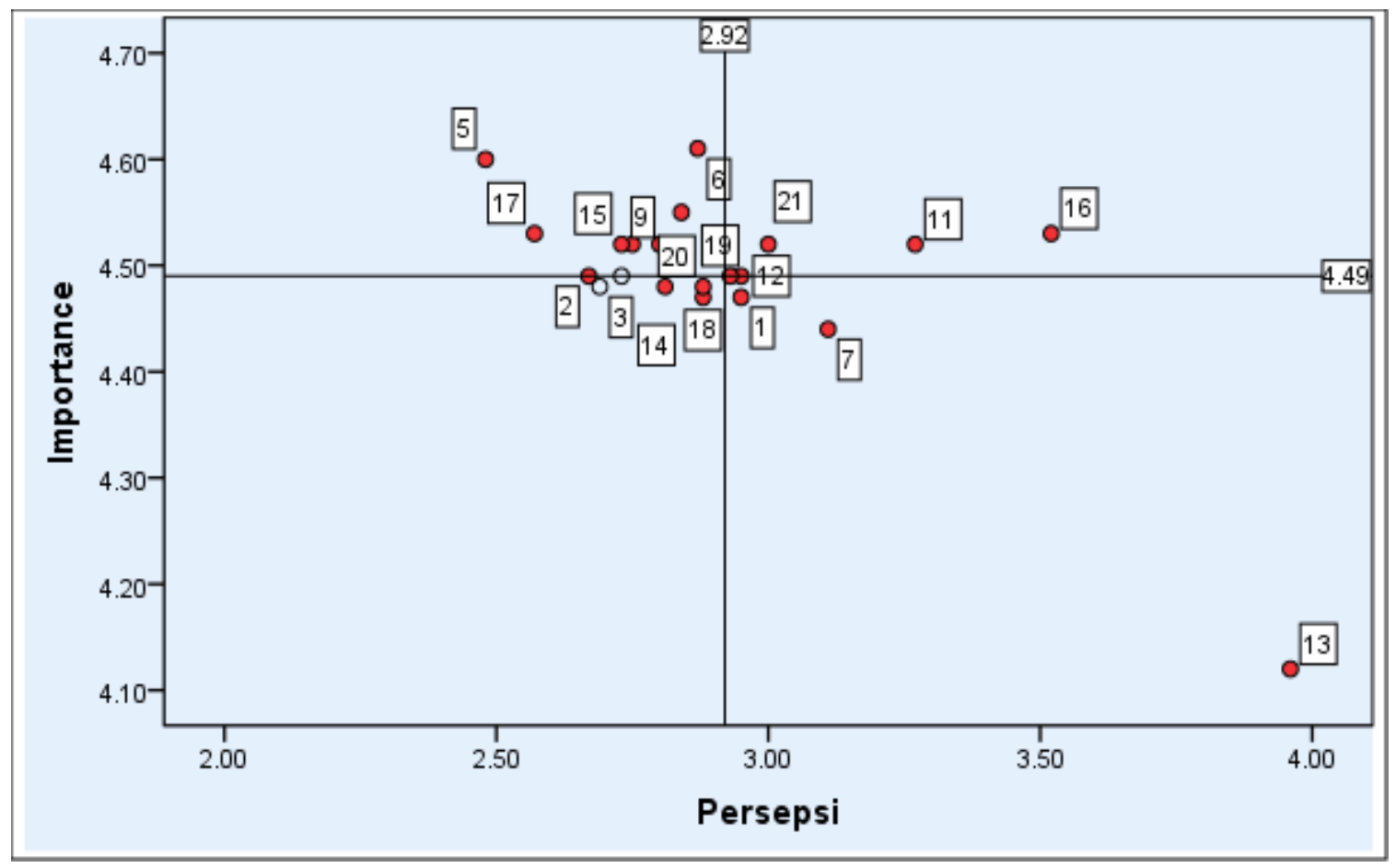

Sumber: data primer pengolahan data

Gambar 1. Matriks Importance Performance Analysis Pelayanan bengkel motor "ABC"

\section{Pembahasan}

Pada perhitungan nilai servqual yang menunjukkan bahwa semua dimensi yang memuat 21 atribut dalam pelayanan bengkel motor $\mathrm{ABC}$ bernilai negative, ini menunjukkan bahwa masih ada kesenjangan antara pelayanan yang diterima oleh pelanggan dengan harapan yang diinginkan oleh pelanggan. Atribut "kelengkapan sparepart" memiliki nilai gap negative paling tinggi yaitu sebesar -2.12. Sementara atribut yang memiliki nilai servqual atau gap paling kecil yaitu sebesar 0,16 adalah atribut "Pihak bengkel bertanggung jawab penuh atas hasil service"

Berdasarkan hasil perhitungan Servqual diperoleh hasil bahwa nilai rata-rata harapan pelanggan adalah sebesara 4.50 lebih tinggi dari nilai rata-rata pelayanan yang dipersepsikan pelanggan adalah 2.92, sehingga dapat dikatakan bahwa kualitas pelayanan dapat dikatakan buruk, dan dari masing-masing dimensi yang memuat 21 atribut pelayanan memiliki nilai negative yang berarti pelayanan yang diberikan oleh bengkel motor ABC belum memenuhi harapan pelanggan atau tidak berkualitas dan harus diperbaiki dengan prioritas perbaikan dimulai dengan dimensi yang memiliki nilai gap paling tinggi.

Dari lima dimensi servqual, dimensi reliability memiliki nilai gap tertinggi yaitu -1.79 kemudian dimensi responsiveness dengan nilai gap -1.60, kemudian dimensi emphaty dengan nilai gap -1.59 kemudian diikuti dimensi tangible dengan nilai gap -1.53 dan terakhir adalah assurance dengan nilai gap -1.35. Setelah diketahui skor servqual selanjutnya dilakukan analisis kepentingan-kinerja. Analisis ini digunakan untuk mengetahui posisi atribut kualitas pelayananbengkel berdasarkan harapan mengenai tingkat kepentingan (ekspektasi) dan kinerja (persepsi) menurut pengguna. Dari gambar IPA dapat dilihat, atribut yang berada pada kuadaran A yitu atribut yang menjadi prioritas perbaikan sebanyak 9 atribut, kemudian dalam prakteknya peneliti hanya mengambil 5 atribut dengan gap tertinggi untuk menjadi prioritas perbaikan, kemudian menggunakan root cause analysis untuk memperoleh akar penyebab permasalahan. 
a. Atribut kelengkapan sparepart

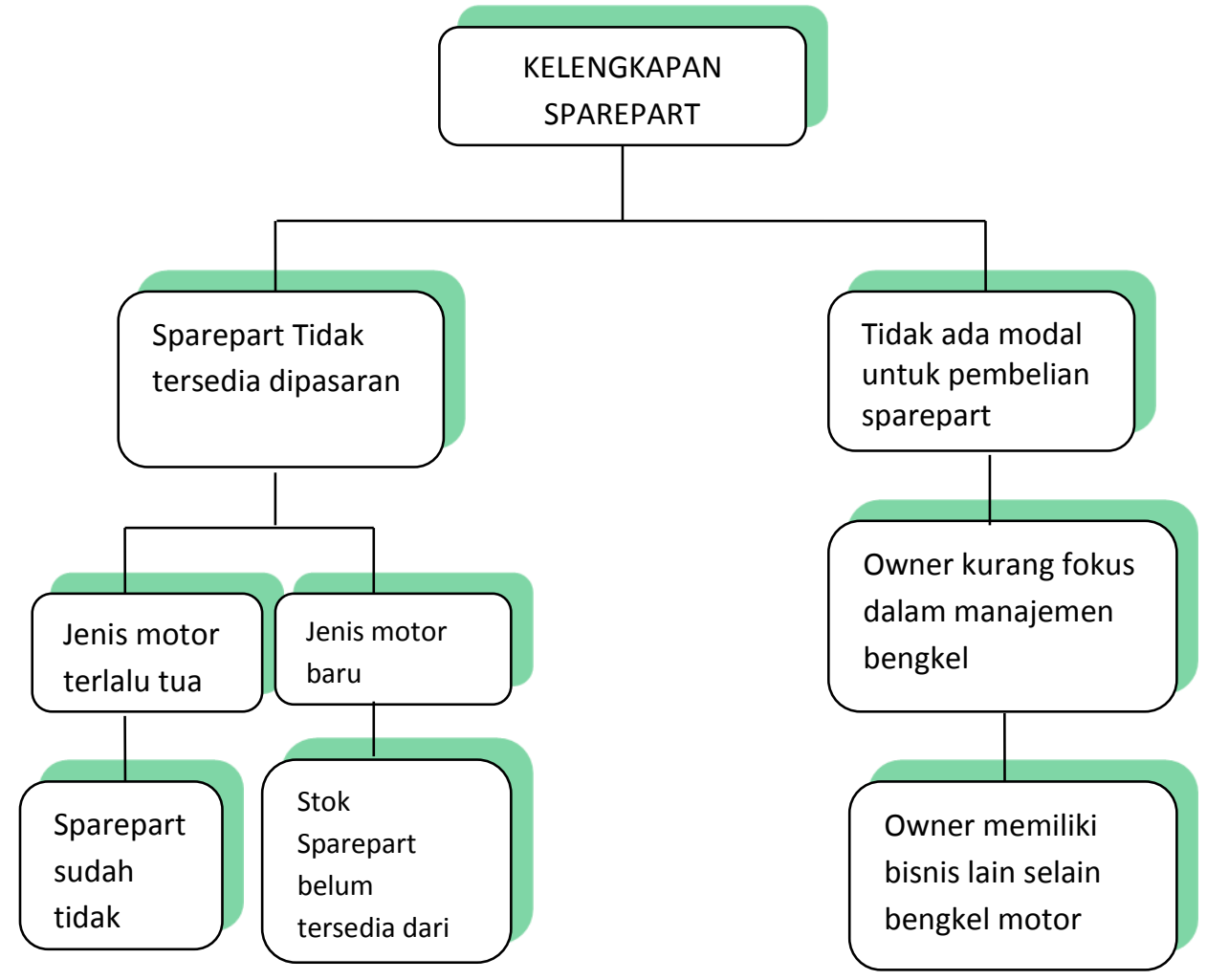

Gambar 2. RCA Atribut Kelengkapan Spare Part

b. Pelayanan yang ramah dari mekanik

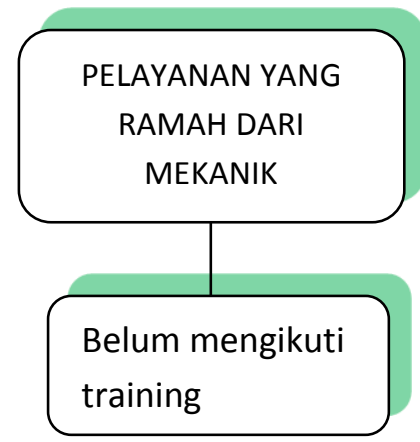

Gambar 3. RCA Pelayanan Yang Ramah dari Mekanik c. Keterampilan Mekanik

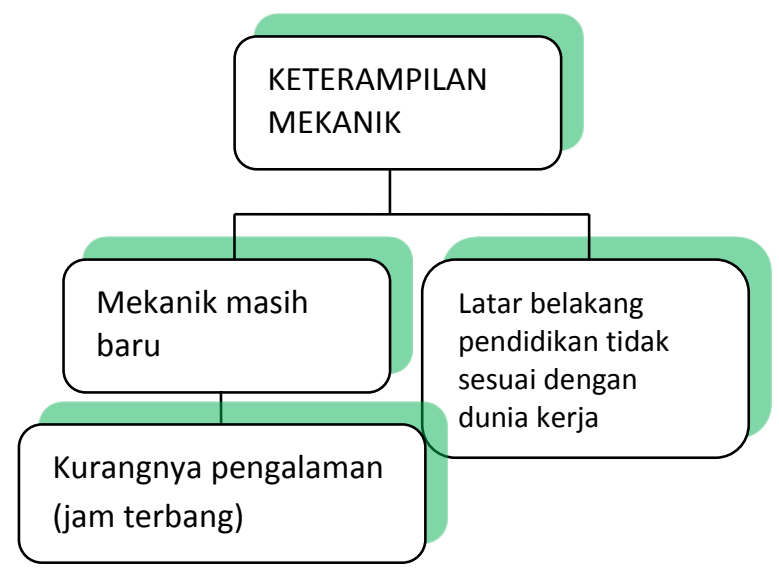

Gambar 4. RCA Keterampilan Mekanik 
d. Kemudahan Pendaftaran Servis

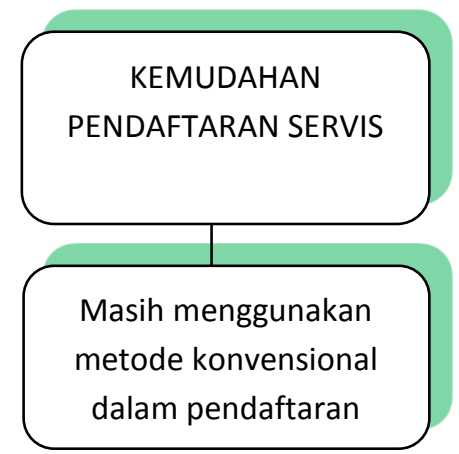

Gambar 5. RCA Kemudahan Pendaftaran servis e. Kualitas servis yang diberikan

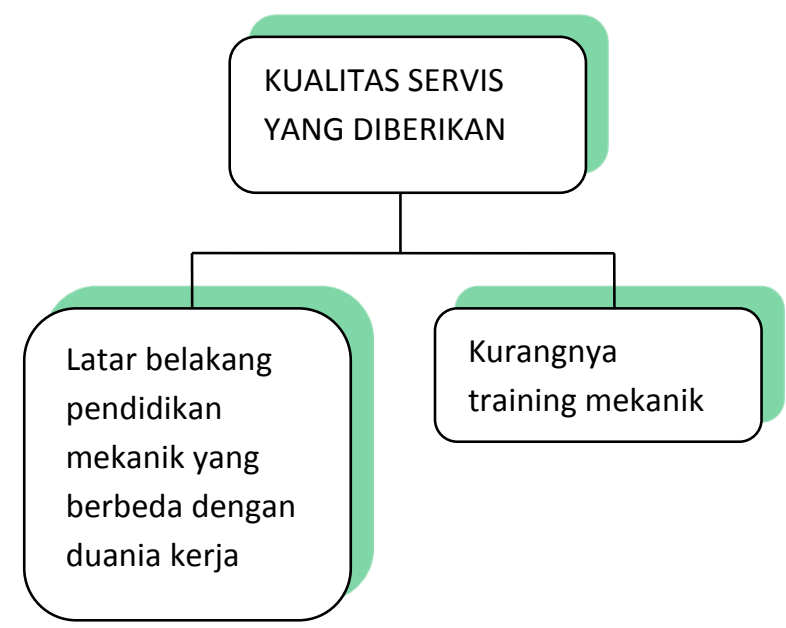

Gambar 6. RCA Kualitas Servis yang Diberikan

Tabel 3 Atribut Prioritas Perbaikan

\begin{tabular}{l|l}
\hline \multicolumn{1}{c|}{ Atribut } & \multicolumn{1}{c}{ Usulan Perbaikan } \\
\hline Kelengkapan sparepart & $\begin{array}{l}\text { Mencari barang dari produsen lain atau barang local } \\
\text { Hot line order } \\
\text { Menambah modal melalui pinjaman }\end{array}$ \\
\hline $\begin{array}{l}\text { Pelayanan yang ramah dan } \\
\text { sopan dari mekanik }\end{array}$ & $\begin{array}{l}\text { Mengikut sertakan mekanik dalam Pelatihan Mekanik yang } \\
\text { sudah dijadwalkan main dealer. }\end{array}$ \\
\hline $\begin{array}{l}\text { Keterampilan Mekanik } \\
\text { Kemudahan Pendaftaran }\end{array}$ & $\begin{array}{l}\text { Mengikut sertakan mekanik dalam Pelatihan Mekanik yang } \\
\text { sudah dijadwalkan main dealer. }\end{array}$ \\
\hline $\begin{array}{l}\text { Servis } \\
\text { misalkan menggunakan aplikasi sms gateway untuk } \\
\text { mempermudah pendaftaran servis }\end{array}$ \\
\hline $\begin{array}{l}\text { Kualitas servis yang } \\
\text { diberikan }\end{array}$ & $\begin{array}{l}\text { Melakukan perbaikan-perbaikan ditiap atribut pelayanan } \\
\text { yang sesuai dengan keinginan pelanggan. }\end{array}$ \\
\hline
\end{tabular}

Sumber: data primer pengolahan data

\section{Kesimpulan}

Dari hasil pengolahan data dengan menggunakan konsep SERVQUAL diperoleh hasil bahwa kualitas dari pelayanan bengkel motor $\mathrm{ABC}$ adalah tidak berkualitas, dengan dimensi Reliability yang menjadi prioritas perbaikan. Sedangkan atribut-atribut yang menjadi prioritas perbaikan berdasarkan hasil Importance Performance Analysis adalah Kelengkapan sparepart, Pelayanan yang ramah dan sopan dari mekanik, Keterampilan Mekanik, Kemudahan Pendaftaran Servis, Kualitas servis yang diberikan. 


\section{Referensi}

Akhlaghi, E, Akhlaghi, H \& Amini, S. (2012) Evaluating educational service quality in technical and vocational colleges using SERVQUAL model. Procedia - Social and Behavioral Sciences. Vol 3, No 46, pp. 5285 - 5289

Albarq, Abbas N. (2013). Applying a SERVQUAL Model to Measure the Impact of Service Quality on Customer Loyalty among Local Saudi Banks in Riyadh. American Journal of Industrial and Business Management, vol 3, No. 20, pp. 700-707.

Behnam, N, \& Joao S. N. (2009). The challenges of six sigma in improving service quality. International Journal of Quality \& Reliability Management Vol. 26 No. 7. pp. 663-68.

Berry, L.B, Zeithaml, V. A, \& Parasuraman, A. (1985). A Conceptual Model of Service Quality and Its Implications for Future Research. Journal of Marketing, Vol 49 pp. 41-50.

Berry, L.B, Zeithaml, V. A, \& Parasuraman, A. (1998). A Multiple-Item Scale for Measuring Consumer Perceptions of Service Quality. Journal of Marketing, Vol 64, No. 1.

Calista, Anggia. (2013). Analisis Pelayanan Jasa Galeri Indosat SA Tuban Dengan Menggunakan Metode IPA dan QFD. Tesis, Magister Teknik Industri, Universitas Mercubuana.

Daniel, B \& Löffler. (2013). Using Critical Incidents to Validate the Direct Measurement of Attribute Importance and Performance When Analyzing Services. Journal of Service Science and Management, vol. 6, no 2, pp. 1-11

Gonçalves, J. R, Pinto, \& Batista, M. J. (2014) An Importance-performance analysis: Revisiting a tool for the evaluation of clinical services. Vol.6, No.5, 285-291

Huang, Yu-Kai. (2009). The Effect of Airline Service Quality on Passengers' Behavioural Intentions Using SERVQUAL Scores: A TAIWAN Case Study. Journal of the Eastern Asia Society for Transportation Studies, 9(20), 70-75.

Kotler, Philip. (2000). Marketing Management: Analysis, Planning, Implementation and Control, Millenium Ed., Prentice Hall Inc., New Jersey.

Lovelock, C.H. and Wright, L.K (1999), Principles of Service Marketing and Management. Prentice-Hall, Inc.

Meng Seng, Nishimoto \& George. (2011). The Use of Importance-Performance Analysis (IPA) in Evaluating Japan's E-government Services. Journal of Theoretical and Applied Electronic Commerce Research. Vol 6, No 2.17-30.

Mohammad, Md. Abdullah \&Dr. Ataur Rahman. (2011). Measuring Service Quality using SERVQUAL Model: A Study on PCBs (Private Commercial Banks) in Bangladesh. Business Management Dynamics.Vol.1, No.1, pp.01-11

Kuo, Nien-Te, \& Chang, Kuo-Chien. (2011). Identifying critical service quality attributes for higher education in hospitality and tourism: Applications of the Kano model and importance-performance analysis (IPA). African Journal of Business Management, 5(30), pp. 12016-12024.

Priyatno. (2012), Cara Kilat Belajar Analisis Data dengan SPSS 20. Andi, Yogyakarta.

Siew-Phaik Loke et al. (2001) Service Quality and Customer Satisfaction in a Telecommunication Service Provider. International Conference on Financial Management and Economics IPEDR, vol.11. no 2

Sugiono, (2012). Metode Penelitian Kuantitatif Kualitatif dan R\&D. Bandung: Alfabeta, CV.

Suryana, (2012). Perbaikan Pelayanan Dibagian Pelayanan Umum Di Sekolah Tinggi XYZ Dengan Servqual. Tesis, Magister Teknik Industri, Universitas Mercubuana.

Tjiptono, (2012). Servis Management Mewujudkan Layanan Prima. Yogyakarta. Andi.

Tileng, M.Y, Utomo, W. H \& Latuperissa, R.(2013) Analysis of Service Quality using Servqual Method and Importance Performance Analysis (IPA) in Population Department, Tomohon City. International Journal of Computer Applications. Volume 70. No.19 (0975 - 8887) 
Tzeng, Gwo-Hshiung, \& Chang, Hung-Fan. (2011). Applying Importance-Performance Analysis as a Service Quality Measure in Food Service Industry, Journal of Technology Management \& Innovation, Vol. 6, no 3, 40-55.

Victor Lorin (2013). The Assessment of Perceived Service Quality of Public Health Care Services in Romania Using the SERVQUAL Scale. International Economic Conference of Sibiu 2013 Post Crisis Economy: Challenges and Opportunities, (pp. 573 - 585). Lucian Blaga: University of Sibiu.

Wijaya, (2011). Manajemen Kualitas Jasa. Jakarta: Indeks, PT

Zeithaml, V. A., Berry, L. L. and Parasuraman, A. (1996). The behavioral consequences of service quality. Journal of Marketing, Vol. 60, 31-52. 